\title{
HOW IS BINOCULARITY MAINTAINED DURING CONVERGENCE AND DIVERGENCE?
}

\author{
S. J. JUDGE \\ Oxford
}

\begin{abstract}
SUMMARY
The geometrical requirements for binocular fusion are stated, and the main features of horizontal vergence eye movements are described, together with an influential schema of understanding the interaction between vergence and accommodation. The anatomy and physiology of the midbrain region implicated in vergence and accommodation control are discussed. The cortical areas from which suitable sensory signals might be derived are mentioned briefly, and a speculation is made about esotropia.
\end{abstract}

\section{GEOMETRICAL REQUIREMENTS FOR BINOCULARITY}

The requirement for single binocular vision in normal human subjects is usually taken to be to have the lines of sight of the two eyes aligned on the target to within a tolerance of a few minutes of arc (Panum's fusional area). The lines of sight need to be aligned horizontally and vertically, and for fusion of a spatially extended stimulus torsion also needs to be matched in the two eyes, but in this paper I shall discuss only horizontal alignment because my focus is on the neural circuits that underlie the behaviour and these have only been investigated for the horizontal system; brief reviews of vertical and torsional vergence behaviour can be found elsewhere. ${ }^{1,2}$

Although Panum's area can be as small as a few minutes of arc wide, it can be much larger. Fender and Julesz ${ }^{3}$ showed that once binocular stimuli are fused, it is possible, using specialised stabilised-vision apparatus, to alter the horizontal binocular disparity by as much as 2 degrees before fusion is lost, although once fusion is lost disparities need to be reduced greatly (approximately to the classical values for Panum's area) for fusion to be regained. In other words there is considerable hysteresis in

Correspondence to: S.J. Judge, University Laboratory of Physiology, Parks Road, Oxford OX1 3PT, UK. Fax: +44 (01865) 272469. e-mail: stuart.judge@physiol.ox.ac.uk. binocular alignment for fusion. It is perhaps therefore not too surprising that when, more recently, accurate binocular measurements were made for the first time in head-free human subjects viewing distant real three-dimensional targets, it was found that variations of vergence of 1-2 (in one subject 5) degrees occurred during head movements of modest velocity without subjects experiencing loss of fusion. ${ }^{4}$

Another caveat that has to be attached to the notion that binocular alignment needs always to be very precise in order for fusion to be maintained, is that the size of Panum's area depends on the sharpness of the target. If the stimulus contains only low spatial frequencies (i.e. is 'blurred') then Panum's area is considerably larger than with high spatial frequency targets. ${ }^{5,6}$

Aside from these qualifications, there is a quite different sense in which it is incomplete - one might even say short-sighted! - to state the requirement for single binocular vision purely in terms of binocular alignment; even modest errors of focus will greatly reduce the available high spatial frequency information unless pupil size is very small, and so the geometrical requirement for good single binocular vision ought, in general, to be three-dimensional and include accommodation being accurate.

\section{CONVERGENCE BEHAVIOUR}

Components of Vergence; Systems Models

The classical view, derived from the work of Maddox, ${ }^{7}$ saw four components to vergence: accommodative (associated in a reflex way with effort to focus on targets), fusional (what we would now call disparity-driven), tonic (that present without a stimulus) and proximal (that related to a subject's knowledge of the target distance, such as might arise, for example, from having seen the layout of the apparatus before the measurements). This categorisation is still influential. Maddox thought that fusional vergence played only a minor role, but by the 1960 s disparity was thought to be more 
important. The study in 1961 by Rashbass and Westheimer $^{8}$ was particularly influential. They showed that subjects respond to suddenly imposed disparity (of up to several degrees) with convergence or divergence eye movements (as appropriate) with a latency of about $160 \mathrm{~ms}$ and a speed roughly proportional to the size of the suddenly imposed disparity - a shorter latency than that of accommodative vergence and a mathematically simple relationship to a cue which is geometrically defined; later in the same decade it was shown ${ }^{9,10}$ that there are cortical neurons that respond selectively to particular horizontal disparities and not others, and this discovery consolidated the view that disparity was indeed of fundamental importance.

Maddox himself had shown that tonic vergence is adjustable. What causes it to change most dramatically is binocular viewing through prisms that require extra convergence. After a few minutes of such prism viewing, adaptation occurs to the prisms, i.e. tonic vergence is biased in a convergent direction (this is most simply shown by measuring vergence in monocular viewing, and finding that phoria has altered), and the bias takes some time to disappear.

The Maddox categorisation leaves out of reckoning several important issues. One complicating factor is that, unknown to Maddox, not only does vergence alter when accommodation is altered, even in monocular viewing when it is unnecessary - 'accommodative-vergence' - but accommodation alters when vergence is altered - 'vergence-accommodation, ${ }^{11}$ - even when no change to accommodation is necessary such as when viewing binocularly in a stereoscope in which each eye views through a pinhole pupil so that the retinal images are always sharp and there is no optical need to alter accommodation. The conventional way of thinking about these effects is to imagine vergence and accommodation as produced by two feedback loops: one with disparity driving vergence, and the other with 'blur' driving accommodation, there being cross-links in both directions between the two loops (Fig. 1). This schema was first suggested by Westheimer ${ }^{12}$ in 1963. The important point to realise about the situation this schema depicts is that the effect a vergence stimulus has depends on what the accommodation stimulus is: the two loops interact (hence the name sometimes given to the schema: the dual-interactive controller). Quite a complex set of measurements is needed to be able to turn such a schema into a quantitative model that matches behavioural data, even for the static situation where neither accommodation nor vergence is changing, ${ }^{13}$ but one point on which there is a great deal of evidence is that vergence response generally matches vergence demand very closely (fixation disparity is very small) - much more closely than accommodation response matches the stimulus - and this means that quantitatively the influence of disparity on vergence (and perhaps also on accommodation) is stronger than that of blur.

There are a number of complications and variations on the above schema, such as those of Schor and Kotulak, ${ }^{14}$ who favour a different position for the cross-links, and that of Zhang et al., ${ }^{15}$ which I shall discuss below. Also, it must be pointed out that while we can at least begin to see how the brain might extract the disparity signal, how 'blur' (which here means the difference between accommodation demand (the reciprocal of target distance) and

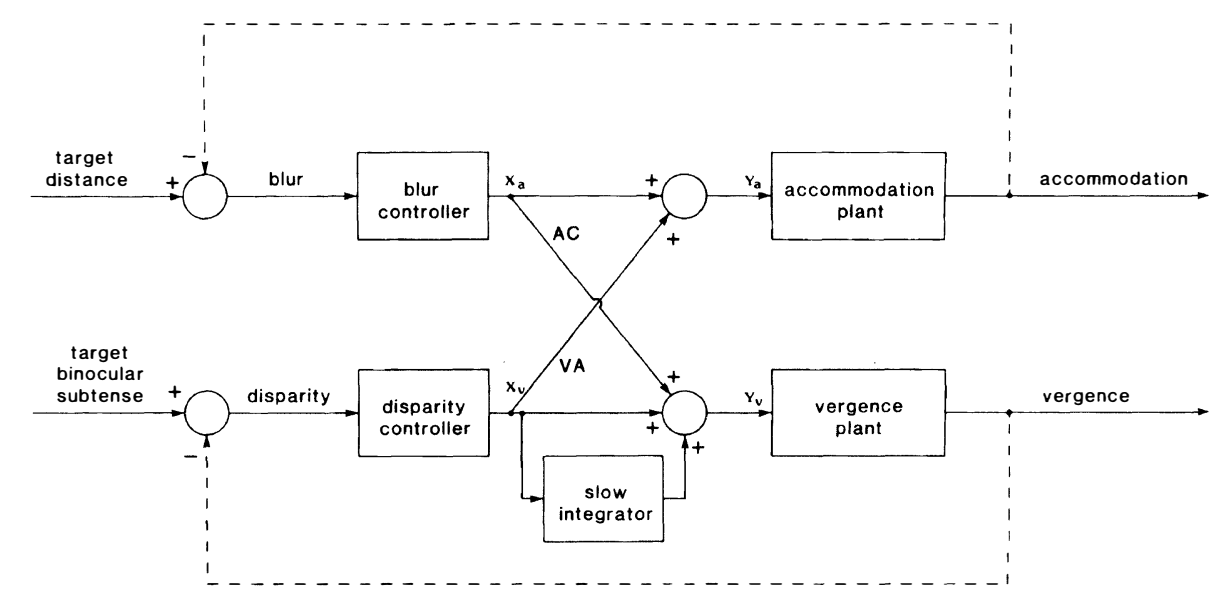

Fig. 1. The dual-interactive controller. Two interacting feedback loops one (upper part of figure) with 'blur' as its error signal and the other (lower part of the figure) with horizontal binocular disparity as its error signal, control vergence (and accommodation). The two feedback loops are not independent, but are cross-linked in both directions: changes in 'blur' alter the drive both to accommodation and to vergence (via the AC or accommodative-vergence cross-link), and changes to disparity alter the drive both to vergence and accommodation (via the VA or vergence-accommodationcross-link). The tonic level of vergence is affected by the recent history of disparity, by means of the 'slow integrator'. The dashed lines indicate effects that arise from the geometry of the situation rather than information flow in the brain. 
accommodation response) is extracted is not obvious. In general, blur is not computable from the retinal image without some additional information. Various suggestions have been made about how this might be done. ${ }^{16}$ The other feature of the schema which should be noted is the box labelled 'slow integrator' parallel to the main output from the disparity controller. This allows the model to prism adapt. Not shown in the diagram is a similar box in the blur pathway, to allow for the adaptable tonic accommodation that Schor et al. ${ }^{17}$ have shown in a minority (less than 25\%: personal communication) of subjects.

\section{Newer Findings}

The idea that vergence movements are small and slow is false, and it is also false that vergence movements are independent of conjugate movements: for example, when looking from a distant target on the left to a nearby one on the right much of the convergence is achieved very rapidly by making a disconjugate saccade which is larger in the left than the right eye. ${ }^{18,19}$ Even when vergence movements are made between binocularly viewed midline targets (so that no saccades occur) large vergence movements can have velocities of 100 degrees per second or more, i.e. well within the saccadic range (though lower than for saccades of the same size).

Moreover, other sensory cues to depth than disparity, such as the expansion of the retinal image of a real object that is approaching, induce vergence. $^{20,21}$

Those who are inclined to doubt whether 'proximal' vergence has any substance might like to know that Enright ${ }^{22}$ has found that accommodative vergence varies with the implied depth of the point fixated when viewing a painting with strong perspective cues.

Busettini et al. ${ }^{23}$ have shown that if large extended stimuli are used, the latency of vergence can be much shorter (about $80 \mathrm{~ms}$ in humans and $50 \mathrm{~ms}$ in monkeys) than the value previously reported ( $c$. $160 \mathrm{~ms}$ ) with small targets (in both species).

\section{ANATOMY AND PHYSIOLOGY}

\section{Ocular Motorneurons}

Although the extraocular muscles are notable for containing a wide variety of different types of muscle fibre, the general view is that there are not special sets of motorneurons for different types of eye movement. ${ }^{24}$

However, Büttner-Ennever and $\mathrm{Akert}^{25}$ have shown that the distribution of the ocular motorneurons in the third nerve nucleus is more complex than previously thought, and that in addition to the main known cell groups there are small motorneurons that project to the orbital layers of the extraocular muscles, where they innervate tonic fibres. It is tempting to speculate that these small motorneurons might have some distinct function, and because they are especially common in the projection to the medial rectus muscle, vergence be implicated, but there is no evidence to support this speculation.

Originally it was thought that individual motorneurons innervating the medial and lateral rectus muscles (those with the greatest role in horizontal vergence movements) discharged equally strongly for vergence or conjugate movements, but the more recent study of Mays and Porter ${ }^{26}$ found a wide variation in the relative strength of the conjugate and vergence signals on individual neurons. Furthermore, in the abducens nucleus, within whose boundaries lie both the lateral rectus motorneurons and also interneurons that carry the main signal that drives the contralateral medial rectus motorneurons in conjugate movements, one does not find that the interneurons are active in conjugate movements but not in vergence, as would be needed to keep the vergence and conjugate signals separate. ${ }^{27}$

\section{Pre-motor Vergence Neurons}

In the pioneering studies in unanaesthetised monkeys of the behaviour of ocular motorneurons in the third nerve nucleus several neurons were noted, dorsolateral to the caudal part of the nucleus, whose discharge appeared to be proportional to the angle of convergence. ${ }^{28,29}$ More recently these neurons have been studied systematically. ${ }^{30,31}$ The majority of these neurons increase their discharge rate in convergence but there are some neurons that decrease their discharge rate in convergence. The neurons do not seem to be divided into categories that relate in any simple way to the Maddox components of vergence, i.e. one rarely sees neurons that are active, say, only in accommodative-vergence and not in disparity-driven vergence. Moreover, because vergence and accommodation are normally closely associated, it is not simple to tell whether these neurons are related to vergence or accommodation. Judge and Cumming ${ }^{31}$ used a stereoscopic apparatus that allowed accommodation and vergence demand to be either normally coupled or dissociated. By comparing the activity of neurons in normal binocular viewing and viewing with conflicting accommodation and vergence demands, they were able to show that some neurons discharged as though they were driving accommodation, some as though they were driving vergence and others in more complex ways. Applying the dual-interactive control model to the situation, they suggested that the explanation of the more complex behaviour of some neurons might be that these neurons received mismatched drive from 'blur' and disparity. This suggestion was followed up by Zhang et al., ${ }^{15}$ who 
showed that one could account for such data by employing a multi-channel version of the dualinteractive controller model. Neurons in channels receiving well-matched blur and disparity-derived inputs would behave appropriately for their motor connections, whereas neurons with modestly mismatched inputs would not do so, and if the mismatch had just the wrong value might even look as though they were related to the opposite response. More importantly, the same group ${ }^{15,32}$ were able to examine the behaviour in normal and conflict viewing of a number of neurons that could be activated antidromically by electrical microstimulation of the medial rectus subdivision of the third nerve nucleus. The activity of these neurons was generally more closely related to vergence than accommodation, with the relationship to accommodation averaging out to zero over the sample.

In a separate study ${ }^{33}$ some of the neurons in the same region were identified as Edinger-Westphal (EW) nucleus neurons by antidromic activation from electrical stimulation of the third nerve (not nucleus). These neurons turned out to have the distinctive property (amongst the near-response neurons in general) of a rather small increase in firing rate as the animal accommodated, so it might in principle be possible to go back through the data from earlier experiments and select out putative E-W cells from others. Tested in conflict viewing, the majority of identified E-W neurons behaved as though they were related to accommodation alone.

Another question asked of the near-response neurons dorsolateral to the third nerve nucleus was how they behave when the animal is adapted to prisms.

This is a difficult experiment because one needs to record from neurons before, during and after prismadaptation. It would appear ${ }^{34}$ that part but not all the tonic vergence signal needed to account for prismadaptation is present on the pre-motor vergence neurons.

There are two other groups of near-response related neurons that have been identified in the midbrain: one near the abducens nucleus ${ }^{35}$ and the other in the pretectum or perhaps in the anterior superior colliculus. ${ }^{30,31}$

In the cortex, the best candidate for a region from which sensory signals might derived for vergence and accommodation control would seem to be the inferior parietal lobule. Damage to this region is known to affect depth perception. ${ }^{36}$ Sakata et al. ${ }^{37,38}$ have found neurons there whose activity is related to distance of fixation, or to tracking of targets moving in depth; and more recently Gnadt and Mays ${ }^{39}$ have described neurons in parietal area LIP that are tuned for eye movements in three-dimensional space. In the cat, Bando's group ${ }^{40,41}$ has found that there are convergence-related neurons in the lateral suprasylvian area, and that electrical stimulation there can elicit small convergence eye movements. Very recently Gamlin et al. (personal communication) have discovered a region of the frontal cortex, just anterior to the saccadic frontal eye fields, where neurons discharge in relation to vergence.

\section{A SPECULATION ABOUT ESOTROPIA}

Attempts to prevent children developing squint still rely largely on the observation made over a hundred years ago by Donders, that esotropic squint is associated (to some degree) with hyperopic refractive errors. By identifying children with high hyperopia early in life, and persuading them to wear corrective spectacles, the incidence of squint can be reduced. ${ }^{42,43}$ Donders supposed that accommodation and vergence were inflexibly linked early in life, and that the effort of the hyperopic child to focus induced inappropriate convergence, which in turn prevented normal development of binocular vision. My interest in this idea is largely in the degree to which the first premise is true. We know very little indeed about vergence early in life. One might speculate that it is only in some children that accommodation and vergence are inflexibly linked at the crucial stage in life. If so, then the Donders esotrope is the unfortunate person who was both hyperopic early in life and whose early accommodation-vergence linkage was inflexible. One point that should be made is that it is not the ratio of accommodation to vergence that needs to be adjusted to make accommodative vergence appropriate in hyperopia, but the bias in vergence - in other words the critical component is the level of tonic vergence.

Supported by the Medical Research Council and the Wellcome Trust.

Key words: Binocularity, Convergence, Divergence, Eye movements, Human, Monkey.

\section{REFERENCES}

1. Judge SJ. Vergence. In: Cronly-Dillon J, editor. Vision and visual dysfunction. Vol 8, Carpenter RHS, editor. Eye movements. London: Macmillan, 1991:157-72.

2. Howard IP, Rogers BJ. Binocular vision and stereopsis. New York: Oxford University Press, 1995.

3. Fender D, Julesz B. Extension of Panum's fusional area in binocularly stabilised vision. J Opt Soc Am 1967;57:819-30.

4. Steinman RM, Collewijn H. Binocular retinal image motion during active head rotation. Vision Res 1980; 20:415-29.

5. Kulikowski JJ. Limit of single vision in stereopsis depends on contour sharpness. Nature 1978;276:126-7.

6. Schor C, Wood I, Ogawa J. Binocular sensory fusion is limited by spatial resolution. Vision Res 1984;7:661-5.

7. Maddox EE. The clinical use of prisms, 2nd ed. Bristol: John Wright, 1893.

8. Rashbass C, Westheimer G. Disjunctive eye movements. J Physiol (Lond) 1961;159:339-60. 
9. Barlow HB, Blakemore C, Pettigrew JD. The neural mechanism of binocular depth discrimination. J Physiol (Lond) 1967;193:327-42.

10. Pettigrew JD, Nikara T, Bishop PA. Binocular interaction on single units in cat striate cortex: simultaneous stimulation by single moving slits with receptive fields in correspondence. Exp Brain Res 1968;6:391-410.

11. Fincham EF, Walton J. The reciprocal actions of accommodation and vergence. J Physiol (Lond) 1957; 137:488-508.

12. Westheimer G. Amphetamine, barbiturates and accommodative convergence. Arch Ophthalmol 1963; 70:830-6.

13. Hung GK, Semmlow JL. Static behavior of accommodation and vergence: computer simulation of an interactive dual-feedback system. IEEE Trans Biomed Eng 1980;27:439-47.

14. Schor CM, Kotulak J. Dynamic interactions between accommodation and convergence are velocity sensitive. Vision Res 1986;26:927-42.

15. Zhang Y, Mays LE, Gamlin PDR. Characteristics of near response cells projecting to the oculomotor nucleus. J Neurophysiol 1992;67:944-60.

16. Flitcroft DI. A neural and computational model for the chromatic control of accommodation. Vis Neurosci 1990;5:547-55.

17. Schor CM, Kotulak J, Tseutaki T. Adaptation of tonic accommodation reduces accommodative lag and is masked in darkness. Invest Ophthalmol Vis Sci 1986;27:186-93.

18. Enright JT. Changes in vergence mediated by saccades. J Physiol (Lond) 1984;350:9-31.

19. Erkelens CJ, Steinman RM, Collewijn H. Ocular vergence under natural conditions. II. Gaze shifts between real targets differing in distance and direction. Proc R Soc Lond B 1989;236:441-65.

20. Erkelens CJ, Regan D. Human ocular vergence movements induced by changing size and disparity. $\mathrm{J}$ Physiol (Lond) 1986;379:145-69.

21. McLin LN, Schor CM, Kruger PB. Changing size (looming) as a stimulus to accommodation and vergence. Vision Res 1988;28:883-98.

22. Enright JT. Perspective vergence: oculomotor responses to line drawings. Vision Res 1987;27: 1513-26.

23. Busettini C, Krauzlis RJ, Miles FA. Short-latency vergence responses. In: Fuchs AF, Brandt T, Büttner U, Zee D, editors. Contemporary ocular motor and vestibular research: a tribute to David A Robinson. New York: Thieme, 1994:312-9.

24. Robinson DA. Control of eye movements. In: Brooks VB, editor. Handbook of physiology, sect 1, The nervous system, vol 2. Bethesda, MD: American Physiological Society, 1981:1273-320.

25. Büttner-Ennever JA, Akert K. Medial rectus subgroups of the oculomotor nucleus and their abducens internuclear input in the monkey. J Comp Neurol 1981;197:17-27.

26. Mays LE, Porter JD. Neural control of vergence eye movements: activity of abducens and oculomotor neurons. J Neurophysiol 1984;52:743-61.

27. Gamlin PDR, Gnadt JW, Mays LE. Abducens internuclear neurons carry an inappropriate signal for ocular convergence. J Neurophysiol 1989;62:70-81.

28. Robinson DA. Oculomotor unit behaviour in the monkey. J Neurophysiol 1970;33:393-404.

29. Schiller PH. The discharge characteristics of single units in the abducens and oculomotor nuclei of the unanesthetised monkey. Exp Brain Res 1970;10: 347-62.

30. Mays LE. Neural control of vergence eye movements: convergence and divergence neurons in midbrain. $J$ Neurophysiol 1984;51:1091-108.

31. Judge SJ, Cumming BG. Neurons in the monkey midbrain with activity related to vergence eye movement and accommodation. J Neurophysiol 1986;55: 915-30.

32. Zhang Y, Gamlin PDR, Mays LE. Antidromic identification of midbrain near response cells projecting to the oculomotor nucleus. Exp Brain Res 1991; 84:525-8.

33. Gamlin PDR, Zhang Y, Clendaniel RA, Mays LE. Behavior of identified Edinger-Westphal neurons during ocular accommodation. J Neurophysiol 1994;72:2368-82.

34. Morley JW, Judge SJ, Lindsey JW. Role of monkey midbrain near-response neurons in phoria adaptation. J Neurophysiol 1992;67:1475-92.

35. Gnadt JW, Gamlin PDR, Mays LE, Zhang Y. Vergence-related cells near the abducens nuclei. Soc Neurosci Abstr 1988;14:612.

36. Andersen RA. The role of the inferior parietal lobule in spatial perception and visual-motor integration. In: Plum F, Mountcastle VB, Geiger SR, editors. Handbook of physiology, sect 1 , The nervous system, vol V, Higher functions of the brain, part 2. Bethesda, MD: American Physiological Society, 1987:483-518.

37. Sakata H, Shibutani H, Kawano K. Spatial properties of visual fixation neurons in posterior parietal association cortex of the monkey. J Neurophysiol 1980;43: 1654-72.

38. Sakata H, Shibutani H, Kawano K. Functional properties of visual tracking neurons in posterior parietal association cortex of the monkey. J Neurophysiol 1983;49:1364-80.

39. Gnadt JW, Mays LE. Neurons in monkey parietal area LIP are tuned for eye-movement parameters in threedimensional space. J Neurophysiol 1995;73:280-97.

40. Takagi M, Toda H, Yoshikawa T, Hara N, Ando T, Abe $\mathrm{H}$, Bando T. Ocular convergence-related neuronal responses in the lateral suprasylvian area of alert cats. Neurosci Res 1992;15:229-34.

41. Toda H, Takagi T, Yoshikawa T, Bando T. Disjunctive eye movement evoked by microstimulation in an extrastriate cortical area of the cat. Neurosci Res 1991;12:300-6.

42. Ingram RM, Walker C, Wilson JM, Arnold PE, Dally S. Prediction of amblyopia and squint by means of refraction at age 1 year. Br J Ophthalmol 1986;70:12-5.

43. Atkinson J. Infant vision screening: prediction and prevention of strabismus and amblyopia from refractive screening in the Cambridge photorefraction program. In: Simons K, editor. Early visual development, normal and abnormal. New York: Oxford University Press, 1993:335-48. 